\title{
Performance and failure analysis of carbon fiber-reinforced polymer (CFRP) strengthened reinforced concrete (RC) beams
}

\author{
Ayesha Siddika $^{1}$ (D) Krishno Saha ${ }^{1} \cdot$ Md. Sumodro Mahmud $^{1} \cdot$ Sumon Chandra Roy ${ }^{1} \cdot$ Md. Abdullah Al Mamun $^{2}$. \\ Rayed Alyousef ${ }^{3}$
}

Received: 27 September 2019 / Accepted: 13 November 2019 / Published online: 16 November 2019

(c) Springer Nature Switzerland AG 2019

\begin{abstract}
At present, the strengthening and retrofitting of reinforced concrete (RC) beams using carbon fiber-reinforced polymer (CFRP) are receiving extensive attention. The use of strengthening technique for $\mathrm{RC}$ beams vary according to purpose. In general, this technique aims to increase load-carrying capacity, either through flexural or shear strengthening. The present study aims to investigate the load-deflection response of CFRP-strengthened RC beams through experimentation with five various strengthening configurations and two different types of surface treatment. The RC beams that were tested in this work were small scale. Results indicate that compared with control beams, CFRP-strengthened beams notably reinforced ultimate load and deflection, as well as ductility, because of the stiffness and grip provided by CFRP. Among the five configurations, the continuous U-wrapping and strip wrapping systems were proven effective for strengthening. A close interaction between internal stirrups and external CFRP strips, which will negatively affect the overall strength of the beams if the reinforcements were placed simultaneously along a similar section of the beam. The failure pattern of the strengthened beams considerably depends on strengthening configuration and internal steel reinforcement, which control the ultimate effectiveness of strengthening. In addition, the ultimate capacity of the beams was predicted in accordance with the $\mathrm{ACl} 440.2 \mathrm{R}-17$ guidelines and was finally compared with the experimental ultimate loads of the CFRP-strengthened beams. Experimental results show that the predicted values were extremely conservative.
\end{abstract}

Keywords Carbon fiber-reinforced polymer $\cdot$ Beam strengthening $\cdot$ Flexure $\cdot$ Shear $\cdot$ Mode of failure

\section{Introduction}

Reinforced concrete (RC) beams typically undergo flexural and shear failure. The load-carrying capacity of most RC beams requires strengthening to resist early failure and prolong service life. RC beams can be strengthened by using several methods; a common method is the use of externally bonded sheets or plates with high-strength materials, such as fiber-reinforced polymer, polyester, steel plates, wire mesh, and textile fabrics [1-5]. Among these materials, carbon fiber-reinforced polymer (CFRP) is widely used for strengthening RC beams. CFRP possesses unique features, such as non-corrosiveness; high longitudinal tensile strength; stiffness; strength-to-weight ratio; resistance to insect, fungi, and chemical attack; low thermal transmissibility; and simple installation [6-11]. These special qualities make CFRP superior over other conventional strengthening materials, such as steel plates, wire mesh, and textiles. In addition, CFRP has a unit weight of $1.5-1.6 \mathrm{~g} / \mathrm{cm}^{3}$, which is considered five times lighter than conventional steel; its tensile strength is 8-10 times higher than that of conventional steel reinforcements

Ayesha Siddika, ayeshace@pust.ac.bd; ayesha.ruet@yahoo.com; $\triangle$ Rayed Alyousef, r.alyousef@psau.edu.sa; Md. Abdullah Al Mamun, mamun_05ce7@yahoo.com | 'Department of Civil Engineering, Pabna University of Science and Technology, Pabna 6600,

Bangladesh. ${ }^{2}$ Department of Civil Engineering, Rajshahi University of Engineering \& Technology, Rajshahi 6204, Bangladesh. ${ }^{3}$ Department of Civil Engineering, College of Engineering, Prince Sattam Bin Abdulaziz University, Alkharj 11942, Saudi Arabia. 
[12]. Meanwhile, improved ductility, flexural strength, shear strength, torsion capacity, and seismic resistance were observed in previously conducted works on CFRPstrengthened beams $[1,9,13,14]$. Therefore, the use of CFRP for strengthening beam elements is increasing.

The performance of strengthened beams is generally controlled by the quality and quantity of strengthening materials, strengthening technique, and loading and environmental conditions. Different types of wrapping systems can be applied to enhance the load-carrying capacity of $\mathrm{RC}$ beams. For instance, applying externally bonded (EB) CFRP along the tension face of a beam element can effectively increase flexural strength [1, 15-17]. EB CFRP can improve the failure of $\mathrm{RC}$ structures from brittle to ductile modes under static and dynamic loadings [18]. The EB wrapping system can provide high strength gain, uniform stress distribution, and up to twice the strength enhancement reported in previous research, where overall effectiveness depends on the CFRP layer, fiber strength, and direction [19]. Typically, fiber reinforced polymer (FRP) sheet wrapped along the tension face of RC beams is an excellent and reliable method for increasing the flexural strength of the beams $[15,16]$. In addition, the U-wrapping FRP system was reported to enhance the flexural strength, stiffness, and deflection resistance of RC beams [15]. Meanwhile, other wrapping systems, such as full and partial wrapping, vertical or horizontal strip-wrapping, and inclined strip-wrapping, can be applied to the beam using CFRP sheets. Moreover, the inclined wrapping system is considered an effective technique for improving the shear strength capacity of RC beams [20]. In addition, FRP wrapping configured along the $45^{\circ}$ direction to the axis of beams can resist diagonal cracks, whereas $0^{\circ}$ and $90^{\circ}$ fiber-oriented strengthened beams are considered less effective [21]. Singh [20] reported an improvement of approximately $11.9 \%$ in the load-carrying capacity of RC beams strengthened with a $45^{\circ}$-oriented CFRP sheet. However, deboning failure at the early stage of loading is a commonly reported problem in EB wrapping [1].

EB CFRP can be applied using adhesives with or without mechanical anchorage systems [22, 23]. The performance of EB FRP-strengthened systems is largely dependent on surface preparation prior to the application of adhesives and FRP. The bonding between adhesive-FRP-concrete cleaning and roughening of the concrete surfaces can be enhanced by sandblasting, water jetting, grinding, brushing, air pressure, and nylon peel-ply techniques $[6,22,24-26]$. A previous study performed a four-point bending test and found that the flexural strength of EB CFRP-strengthened beams increased by 74\% [27]. Ref. [28] proposed that approximately $32.4 \%$ load-carrying capacity can be increased by strengthening RC beams using CFRP strips and by applying the EB technique. The
CFRP vertical-strip wrapping system is efficient in terms of reducing the crack width by up to $20 \%$ [29]. Moreover, wrapping along the $45^{\circ}$ direction efficiently improved ductility and increased shear and torsional strength [30, 31]. Although beams were strengthened in terms of shear capacity, the internal steel reinforcement and spacing of EB CFRP strips along with the fiber direction play important roles in the effectiveness of strengthening [32-34].

Several studies reported that brittle debonding failure is a common failure mode of the CFRP strengthening system $[17,18]$. In general, early debonding prevents the CFRP composites from reaching ultimate strain and reduces ultimate load. This phenomenon occurs when the bond strength between concrete and CFRP is low. Meanwhile, fiber strength reduction may be induced along the sharp corners of $\mathrm{RC}$ beams when they are wrapped directly with CFRP sheets [30]. Therefore, surface treatment is required. In several cases, section modification is beneficial for enhancing the bonding between concrete-epoxy-CFRP. Surface preparation often fails to prevent debonding, but it can delay debonding and increase the load-carrying capacity of beams [22]. To achieve the highest utilization of CFRP strain and steel materials, the interaction between internal reinforcements and EB CFRP must be analyzed in terms of design, and preventive measure should be taken to delay debonding prior to reaching ultimate strength.

This study aims to investigate the load-carrying capacity and failure characteristics of EB CFRP-strengthened smallscale beams with various strengthening configurations and surface treatments. In addition, this study examined the interaction between internal steel reinforcement and EB CFRP sheets. Previous studies focused on full-scale RC beams with specific configurations for specific strengthening purposes, such as flexural strengthening, EB U-wrapping, tension face wrapping, and shear strip wrapping $[1,18]$. In the present study, the selected RC beams were small scale, and their strengthening configurations were not specific for flexural or shear capacity. Strengthening mainly aims to investigate the load capacity improvement and failure characteristics of similar RC beams with various surface treatments and strengthening systems. The ultimate load capacity of the tested beams was calculated and compared with the test results in accordance with the guideline for CFRP strengthening provided by $\mathrm{ACl} 440.2 \mathrm{R}-$ 17 for validations [35].

\section{Experimental program}

\subsection{Material properties and specimen preparation}

The concrete mix for the specimens were prepared using ordinary Portland cement (OPC 43 grade, which conforms 
to the requirement of the IS 8112 standards) [36], coarse sand, and crushed stones. A water-cement ratio of 0.45 was maintained, and water temperature was set to $23-25{ }^{\circ} \mathrm{C}$ during the preparation of the mixture. Table 1 provides the proportion used for mixing concrete. The specific gravity of sand is 2.60 with a fineness modulus of 2.52. Downgraded crushed stones with a maximum size of $20 \mathrm{~mm}$ and a specific gravity of 2.64 were used for specimen preparation. The designed compressive strength of concrete was $25 \mathrm{MPa}$. Concrete cylinders with a diameter of $100 \mathrm{~mm}$ and a height of $200 \mathrm{~mm}$ were prepared to observe their compressive and splitting tensile strengths. The present experiment used small-scale beams, and the test results were compared with those of previous studies on full-scale specimens. The beam specimens were $150 \mathrm{~mm} \times 150 \mathrm{~mm} \times 700 \mathrm{~mm}$ in size and reinforced with four $12 \mathrm{~mm}$-diameter mild steel deformed bars; two of which were placed along the soffit, and another two at the top. The stirrups were composed of $8 \mathrm{~mm}$-diameter deformed bars placed at a distance of $150 \mathrm{~mm}$ from center to center. The reinforcements were secured with a $25-\mathrm{mm}$ concrete cover. The yield and ultimate strengths of the $12 \mathrm{~mm}$ and $8 \mathrm{~mm}$ steel reinforcement were $423 \mathrm{MPa}$ and $619 \mathrm{MPa}$ and $414 \mathrm{MPa}$ and $625 \mathrm{MPa}$, respectively. The casted beams were cured in water for 28 days. Subsequently, the specimens were prepared for strengthening. The manufacturer's specifications were followed to strengthen the CFRP sheets. The ultimate tensile strength, tensile modulus, and ultimate elongation of the CFRP composite are $1250 \mathrm{MPa}, 122 \mathrm{GPa}$, and $1.0 \%$, respectively.

Table 1 Proportion of concrete mix

\begin{tabular}{lccc}
\hline Cement & Water & Sand & Crushed stone \\
\hline Material of concrete & per cubic & meter $(\mathrm{kg})$ & \\
380 & 171 & 757 & 1487 \\
\hline
\end{tabular}

Two-part epoxy resin was used as adhesive, which was mixed at a 1:2 ratio, as specified by the manufacturer. $A$ primer was also used before applying the epoxy resin. The density of the primer was $1.14 \mathrm{gm} / \mathrm{cm}^{3}$, whereas the density of the epoxy (La StrucWrap) saturant was $1.25 \mathrm{gm} /$ $\mathrm{cm}^{3}$. The curing time for the hardening of the saturant with composite was 7 days at $30^{\circ} \mathrm{C}$. Figure $1 \mathrm{a}$, b presents a cross-sectional view of the beam specimens. Each type of the strengthening system was applied on three specimens. The beams were tested, and the load and displacements for first cracking, ultimate point, and at failure were recorded.

\subsection{Strengthening procedure}

The water-cured specimens were dried at normal room temperature (i.e., average of $27-30^{\circ} \mathrm{C}$ ) for three days and prepared for strengthening using CFRP sheets. First, the surface of the specimens was prepared for CFRP application using two methods. Two types of specimens were tested in terms of surface preparation. The first type was continuous abrading (CA), that is, the entire strengthening surfaces were prepared by continuous mechanical abrasion, and the loose materials were cleaned using a soft brush. The second type was the strip abrading (SA) system, where 2-mm strips were prepared for the strengthening surfaces of the RC beams at a spacing of $20 \mathrm{~mm}$ using the sharp edges of a steel plate. The strips were made along the short direction of each face of the beams. The prepared surfaces of the concrete beam were cleaned using a soft brush, and all loose materials were removed. The primer was then applied on the specimen surface. The epoxy mixture was applied after the primer surface hardened for approximately $24 \mathrm{~h}$, and CFRP sheets were attached to the specimen along the selected configuration. Mixtures of the saturant and hardener were applied on

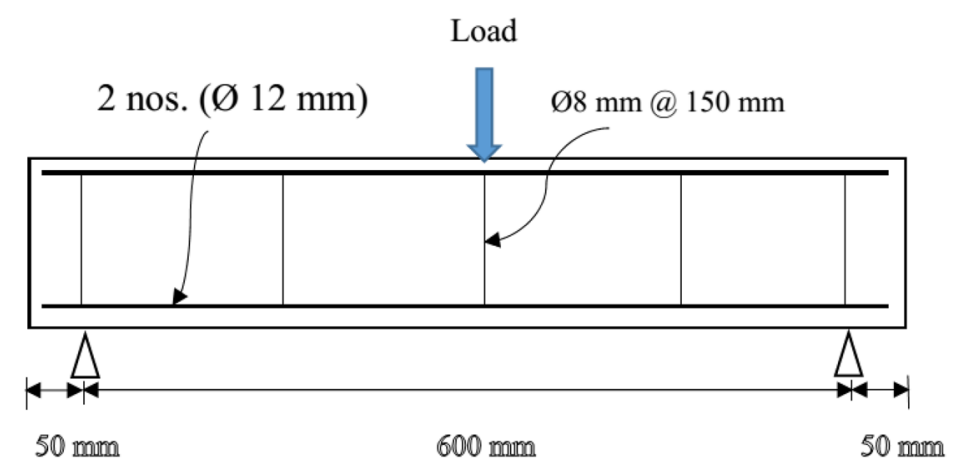

(a) Reinforcement details of RC beam

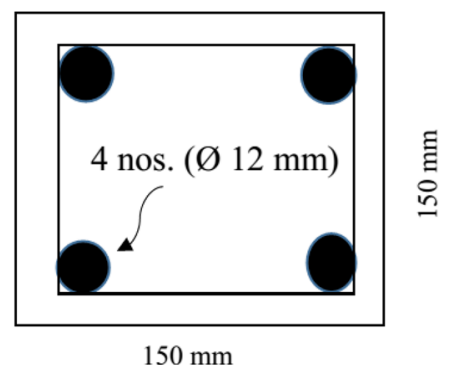

(b) Cross-section of beam

Fig. 1 Reinforcement details and test set-up of the beam specimens 
top of the CFRP sheets and cured for 7 days at $30{ }^{\circ} \mathrm{C}$. The strengthened beams were classified into six types according to the strengthening configuration as follows:

(1) No strengthening applied (C).

(2) Strengthening was applied only on the tension face of the beam (B1). A CFRP sheet was attached along the full width and length of the soffit of the beams and denoted as B1CA and B1SA based on surface treatment.

(3) U-wrapped (B2): Three sides of the beam were wrapped using continuous CFRP sheets and denoted as B2CA and B2SA based on surface treatment.

(4) Strip wrap: CFRP strips, which were $50 \mathrm{~mm}$ and spaced at $150 \mathrm{~mm}$ from center to center, were placed along the internal stirrups (B3).

(5) Strip wrap: CFRP strips (50 $\mathrm{mm}$ and spaced at $175 \mathrm{~mm}$ from center to center) were placed mid-point between two internal stirrups (B4).

(6) Cross strip-wrapped (B5): Strips with a width of $50 \mathrm{~mm}$ were wrapped along three sides of the beams with an angle of $45^{\circ}$ to resemble two $X$ (cross)-like patterns along the soffit of the beams.

Figure $2 a-d$ illustrates the preparation of the specimens for strengthening. The surface treatment of nearly all other specimens, except for B1SA and B2SA, were carried out by applying the mechanical CA technique. Figure $3 a-e$ shows the strengthened specimens with different FRP wrapping configurations.

\subsection{Experimental test set-up}

Three-point bending test was conducted on the beam specimens, and the load-carrying capacity and flexural strength were evaluated by following the ASTM C78 guidelines [37]. During the test, a constant $1 \mathrm{~mm} / \mathrm{min}$ displacement-controlled loading rate was applied on each beam specimen using a universal testing machine (UTM) with a load capacity of $2000 \mathrm{kN}$. The clear span of the beam for the three-point bending test was $600 \mathrm{~mm}$. Figure 1a presents the test set-up. The first crack load (Pc), ultimate load $(\mathrm{Pu})$, and corresponding defects were recorded during testing until specimen failure. During testing, the first crack that appeared for corresponding loads in the test beam was recorded as the cracking load (Pc) of such beam. The vertical deflection of the beam at the point of loading at the first crack load was also recorded as deflection at cracking load. The peak load and corresponding deflection were also recorded from the load cell and deflection scale of the UTM. The peak load before failure of the specimen was recorded as ultimate load $(\mathrm{Pu})$. The vertical deflection of the beam at the loading point was also recorded during beam failure.

\section{Prediction of ultimate load-carrying capacity based on ACI 440.2R-17}

The moment capacity of the strengthened beam was calculated on the basis of the guidelines for flexural strengthening of $\mathrm{RC}$ beams using EB CFRP sheets as provided by $\mathrm{ACI}$

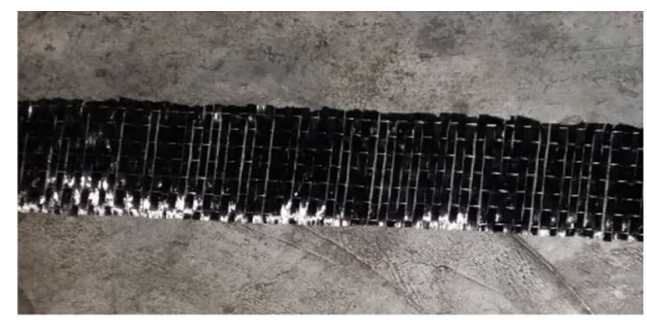

(a) CFRP

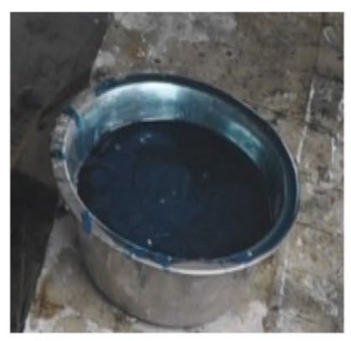

(b) Epoxy composite

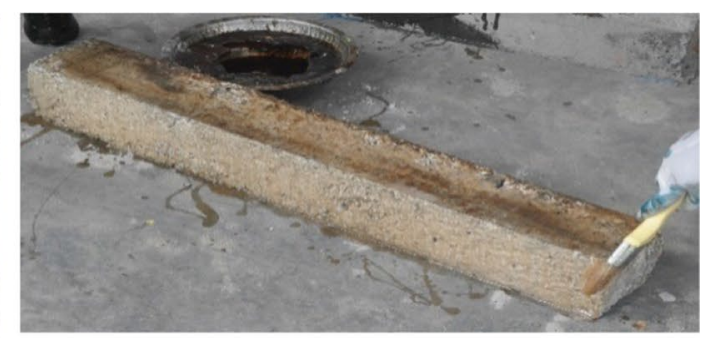

(c) Application of primer to beam surface

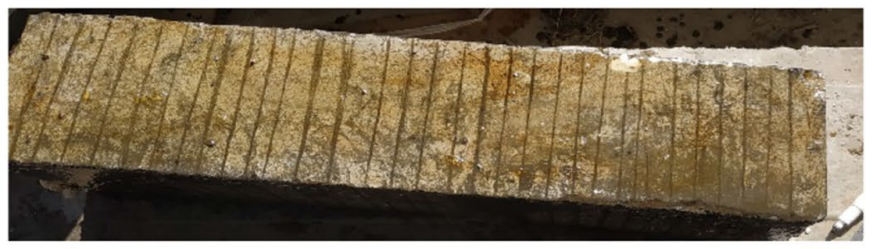

(d) SA surface-treated specimen

Fig. 2 Preparation of specimens for strengthening

SN Applied Sciences 


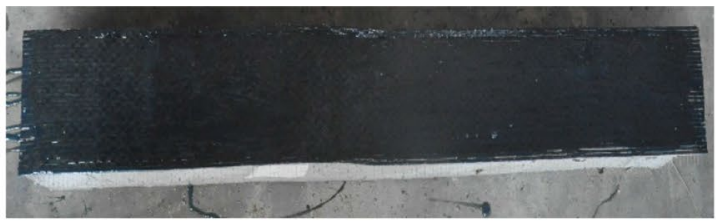

(a) B1

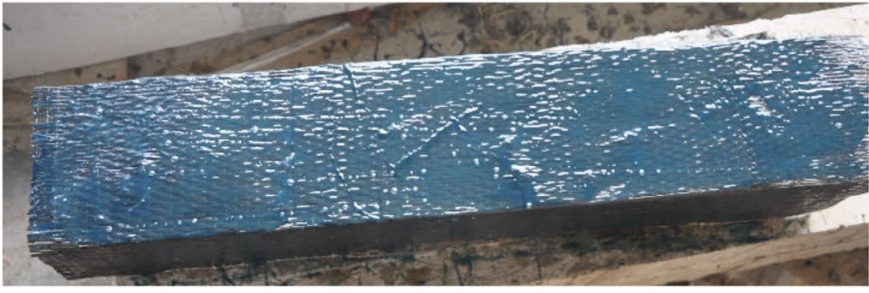

(b) B2

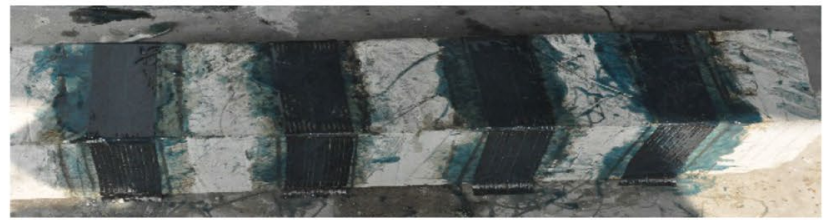

(d) B4

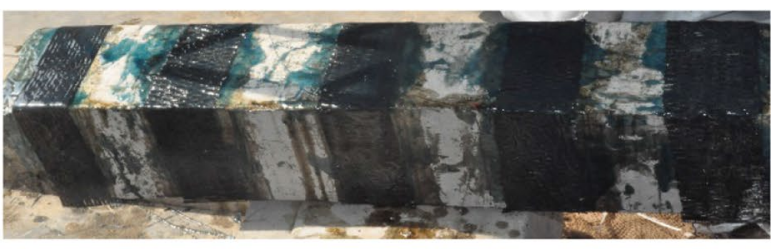

(c) B3

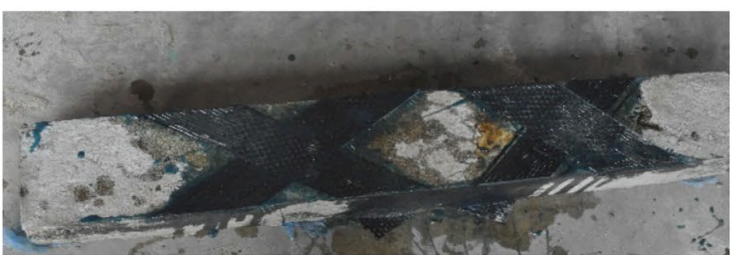

(e) B5

Fig. 3 Strengthened specimens

440.2R-17 [35]. Equation (1) pertains to flexurally strengthened beams with cross-sections, as shown in Fig. 4a:

$M_{n}=A_{s} f_{s}\left(d-\frac{\beta_{1} c}{2}\right)+\Psi_{f} A_{f} f_{f e}\left(d_{f}-\frac{\beta_{1} c}{2}\right)$,

where $f_{f e}=E_{f} \varepsilon_{f e}=$ effective stress in the CFRP composite; $f_{s} \leq 0.80 f_{y}=$ effective stress of internal steel; $\Psi_{f}=0.85$ and $\emptyset=0.90$ for flexure; $\beta_{1}=0.80$ for concrete at $29 \mathrm{MPa}$; and $c$ distance from the extreme compression fiber to the neutral axis.

Additionally, the ACl 440.2R-17 [35] guidelines provided equations for the shear capacity of strengthened beams using CFRP strips. The equation for the cross-section, as shown in Fig. 4b, are presented as follows:

$\emptyset V_{n}=\emptyset\left(V_{c}+V_{s}+\Psi_{f} V_{f}\right)$,

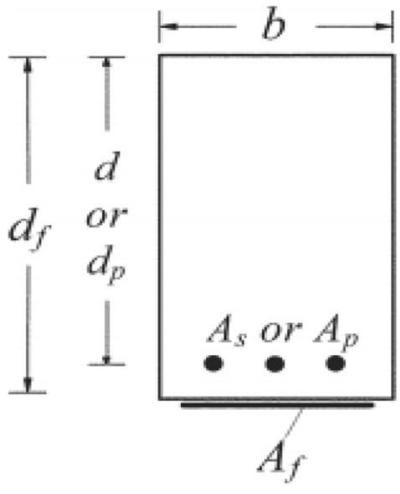

(a) Flexurally strengthened beam using EB CFRP
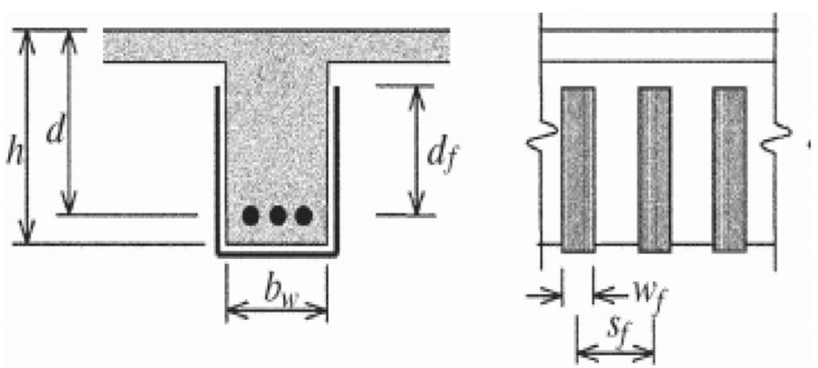

(b) Shear-strengthened beam using EB CFRP strips

Fig. 4 CFRP-strengthened sections of beams 
where $V_{f}=\frac{A_{f v} f_{f e}(\sin \alpha+\cos \alpha) d_{f v}}{s_{f}}=$ shear carried by the CFRP strips; $A_{f v}=2 n t_{f} w_{f}=$ EB CFRP stirrup area; $n=$ number of CFRP layers; and $t_{f}=$ layer thickness.

In addition, the maximum shear capacity of internal steel and EB CFRP stirrups must adhere to the following margin:

$V_{s}+V_{f} \leq 0.66 \sqrt{f}_{c}^{\prime} b_{w} d$,

where $\emptyset=0.75$ for shear.

In addition, the guidelines for shear carried by concrete and steel followed the conventional design as specified in $\mathrm{ACl}$ 440.2R-17 [35].

\section{Experimental findings}

\subsection{Load-deflection characteristics}

The average compressive strength and splitting tensile strength of the cylindrical concrete specimens after 28 days of curing were $29 \mathrm{MPa}$ and $2.74 \mathrm{MPa}$, respectively. Table 2 summarizes the results obtained from the threepoint bending test on control and CFRP-strengthened beams. All beams displayed similar internal steel reinforcements, in which only the strengthening parts differed. In general, a significant improvement in load capacity was observed after strengthening the beams using CFRP. As observed, the first crack loads were independent of the strengthened system but dependent on concrete and steel properties. Therefore, the first crack load cannot be used as a parameter for categorizing the strengthening system in this study. However, the first crack load is generally expected to increase after the beam was strengthened because of the confinement and grip of the CFRP sheets over concrete. Therefore, large deflection was observed under load for cracking in concrete, which is an efficient sign of concrete confinement caused by strengthening. When the beams reached the steel yield point, a swift increase in deflection was observed. Subsequently, CFRP began to carry the load. Therefore, load capacity of strengthened beams was increased, whereas the rapid increment in deflection resulted in high tensile stress in concrete and concrete failure. To reiterate, the ultimate load capacity of the beams was improved after strengthening by approximately $1.7-60.9 \%$ of the control beams, which is dependent on the configuration and surface treatment. Although the beams were small-scale, the trend of increasing capacity is in agreement with the findings of previous studies on beam strengthening using CFRP [15, 16, 38-40]. The beams were loaded until the concrete and CFRP failed. As observed at failure, the deflection of the strengthened beam was more than the control because the grip and confinement of the CFRP prevented the concrete from spalling up to rupture. An increase of approximately 4.3-139.3\% in deflection was observed for the CFRP-strengthened beams compared with the control specimens. Therefore, the strengthened beams reached higher steel yields than the control beam.

\subsubsection{Comparative study on configuration}

The load-carrying capacity of the beams largely varied on the strengthening configuration. A single layer CFRP sheet along the soffit can improve the load-carrying capacity by approximately $10 \%$, which also depends on surface treatment. In addition, the B2 type of strengthening configuration was proven the most efficient technique because its EB CFRP area was higher than those of the other specimens. Figure 5 shows the variation in ultimate flexural strength compared with control beam, which is expressed in percentage. The load capacity for specimens B1CA, B1SA, B2CA, B2SA, B3, B4, and B5 improved by $9.61 \%, 5.43 \%, 60.91 \%, 13.43 \%, 2.10 \%, 28.03 \%$, and 1.74 , compared with the control beams $\%$, respectively.

A direct comparison between the flexural strength capacities of the beam specimens is impossible because the B1 and B2 configurations are generally used for flexure, whereas the others are used for shear strengthening
Table 2 Load capacity and deflection of beams

\begin{tabular}{lcclll}
\hline Specimen & $\begin{array}{l}\text { Cracking load, } \\
P_{\mathrm{c}}(\mathrm{kN})\end{array}$ & $\begin{array}{l}\text { Ultimate load, } \\
\mathrm{Pu}(\mathrm{kN})\end{array}$ & $\begin{array}{l}\text { Deflection at Pc } \\
(\mathrm{mm})\end{array}$ & $\begin{array}{l}\text { Deflection at Pu } \\
(\mathrm{mm})\end{array}$ & $\begin{array}{l}\text { Deflection at } \\
\text { failure }(\mathrm{mm})\end{array}$ \\
\hline $\mathrm{C}$ & 74.12 & 90.13 & 3.72 & 4.91 & 14.29 \\
B1CA & 72.17 & 98.79 & 4.19 & 5.2 & 19.24 \\
B1SA & 62.39 & 95.02 & 2.95 & 5.74 & 14.91 \\
B2CA & 112.31 & 145.03 & 3.98 & 8.24 & 34.19 \\
B2SA & 99.46 & 102.23 & 5.2 & 7.35 & 22.03 \\
B3 & 74.1 & 92.02 & 3.74 & 5.12 & 17.4 \\
B4 & 97.04 & 115.39 & 4.11 & 5.94 & 23.05 \\
B5 & 89.94 & 91.7 & 3.65 & 8.81 & 28.61 \\
\hline
\end{tabular}




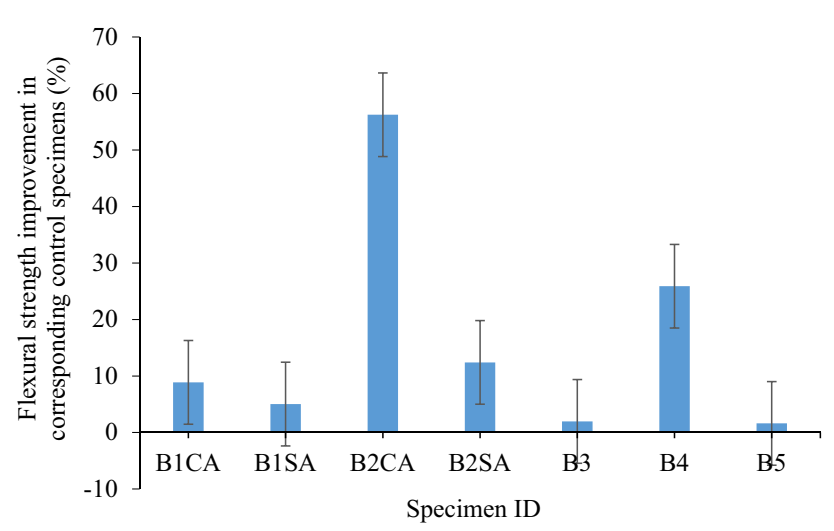

Fig. 5 Improvement in flexural capacity of CFRP strengthened beam

in previous studies $[15,16,40]$. However, in terms of the results of the three-point bending test, the flexural capacity of the beams was calculated, and their variation was investigated. The B2 configuration is the most efficient system for determining the flexural capacity of the beams. However, the cross-pattern in $\mathrm{B} 5$ was not a feasible application for strengthening.

\subsubsection{Comparative study on surface preparation system}

Surface preparation using the mechanical abrasion system is a beneficial method for improving the bond strength between CFRP sheet and concrete $[22,24]$ and for eliminating early debonding. As observed for specimens with varying surface treatments, this statement is in agreement with the observed results. The SA treatment was proven a less effective technique for load carrying and bond strength capacity compared with the $C A$ treatment. The B1CA specimen can carry approximately $4 \%$ more load than the B1SA beam because the high level of bonding with CFRP sheet improved the stiffness of concrete and increased load capacity. This finding is apparent for the U-wrapped system. As observed, the B2CA specimen can carry approximately $42 \%$ more load than the B2SA beam. That is, the former reached CFRP rupture, whereas the latter failed in terms of debonding under low load. The beam surface was rougher in the CA system compared with the SA system. Wide spaces of RC beam surfaces were left smooth without any pretreatment because the strips are only $2 \mathrm{~mm}$ in width and spaced at $20 \mathrm{~mm}$ in the SA system. Thus, the key for interlocking between the CFRP-adhesives and beam surface was lower in the SA process compared with the CA process. Therefore, the SA system was less effective than the CA system.

\subsection{Failure characteristics}

Three failure modes were observed during the flexural testing of the strengthened beams. Mode 1 corresponds to steel yielding after concrete crushing. Mode 2 denotes concrete crushing with CFRP rupture by steel yielding, whereas mode 3 pertains to steel yielding with CFRP debonding. Figure 6 depicts the failure patterns of all strengthened specimens. Mode 1 was only observed in the control specimens, Mode 2 was observed in the B1CA, B1SA, B2CA, B4, and B5 specimens, and Mode 3 was observed for the B2CA, B2SA, and B3 specimens. In all failure modes, the concrete on the beams was severely damaged, except for beam specimens B2CA and B2SA. During loading, the beam specimens first cracked and displayed increased beam deflection along with steel yielding. Furthermore, increased crack widths in concrete were noted. When the concrete in the control specimens reached peak strains during compression, concrete failure occurred with steel yielding. However, deflection failure showed that if the concrete was strong, then the beam can withstand increased steel yielding. For specimen $\mathrm{B} 1$, the beams were CFRP-strengthened along the soffit. Specimen without surface treatment evidently showed improvements in load-carrying and deflection capacities. In Fig. 6, diagonal cracks in the concrete of the B1CA and B1SA specimens were evident after reaching full capacity without deteriorating the bonding between concrete and CFRP sheets. After exceeding the full strength of the beam, the concrete crushed tangentially along with the rupture of the FRP. Two types of failure pattern were observed for B2 as a result of the surface treatment system. In the B2CA specimens, tiny cracks in concrete were observed along the maximum moment region directly under the load point. These cracks widened with the increase in load and caused maximum tension in the beam soffit. Although the two other vertical faces of the beams exhibited sufficient confinement and stiffness, a small debonding was initiated under the load point. Before debonding extended, the CFRP sheet along the bottom and midpoint of the vertical faces ruptured. This failure was mainly influenced by CFRP rupture, and maximum steel yielding was also observed for this beam. Therefore, this beam reached the ultimate strain in CFRP. However, for a similar configuration with SA surface treatment (B2SA), debonding failure initiated in the early stage of loading, which prevented sufficient steel yielding and led to failure in lower load compared with other systems.

Diagonal cracks in the beams prove the low shear strength capacity of the specimens. Most of the beams cracked under the point load and spread diagonally to the beam and reached the bottom face at the failure load. The shear cracks were inclined at an angle of approximately 


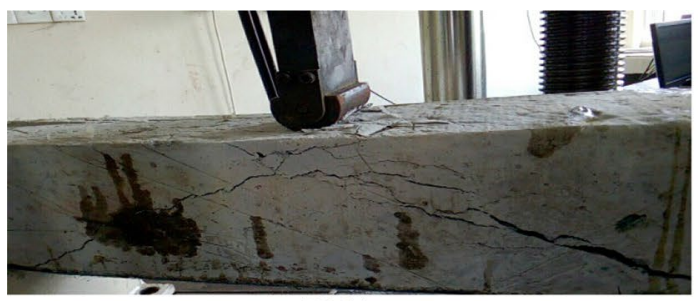

B1CA

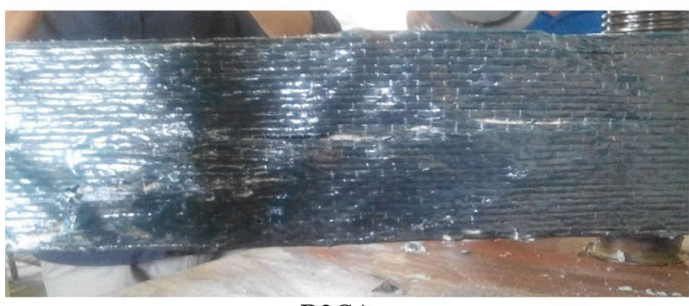

$\mathrm{B} 2 \mathrm{CA}$

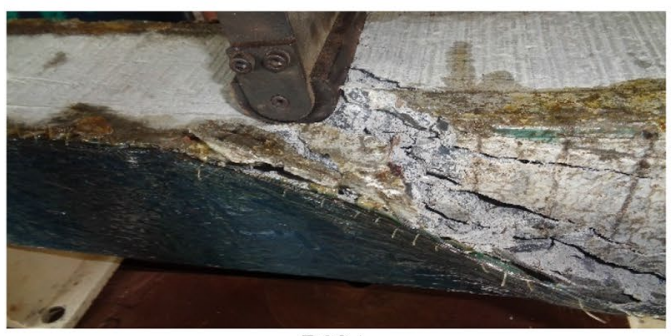

B2SA

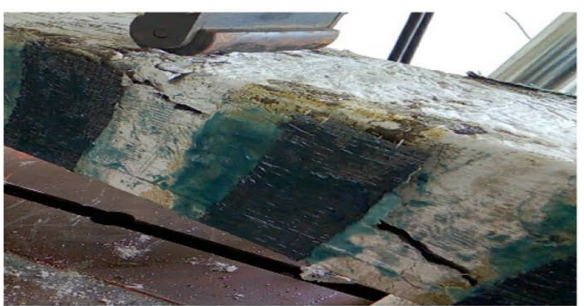

B3
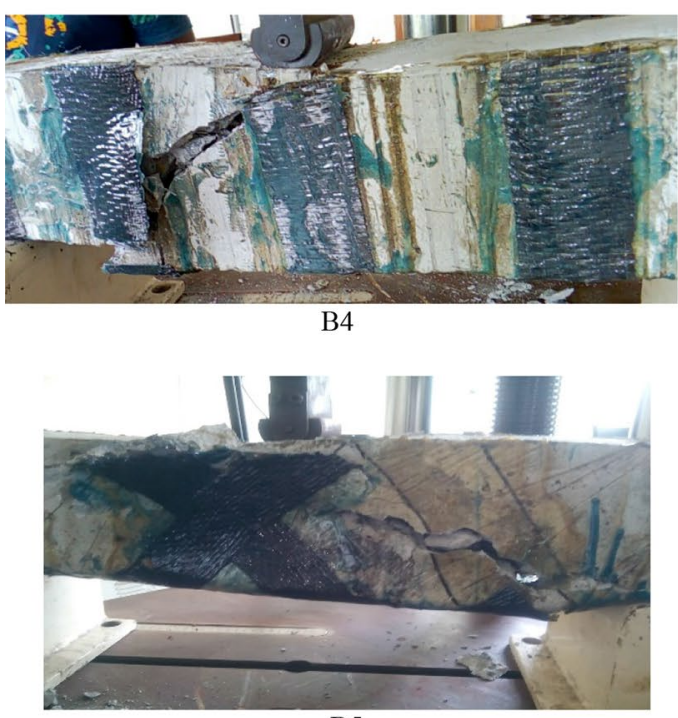

B5
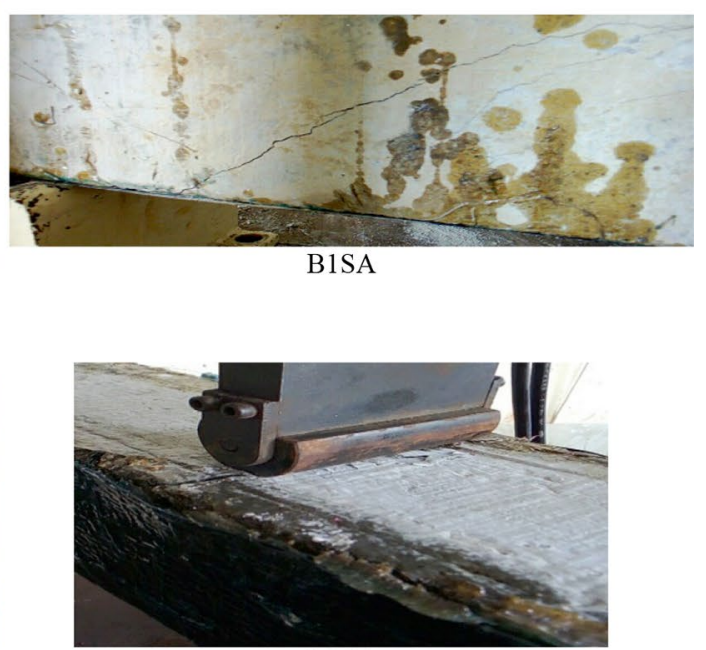

B2CA

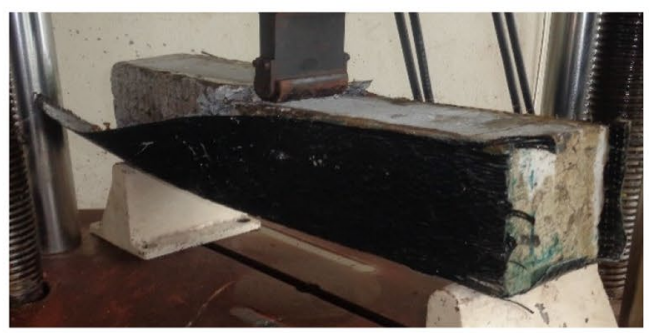

B2SA

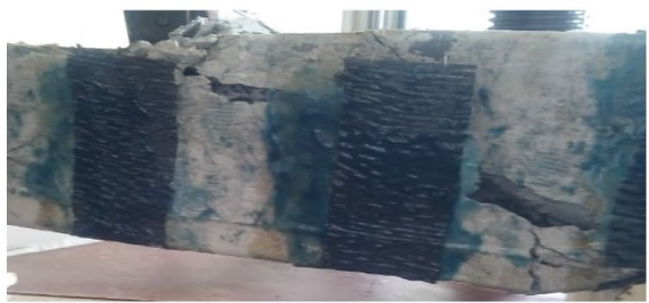

B3

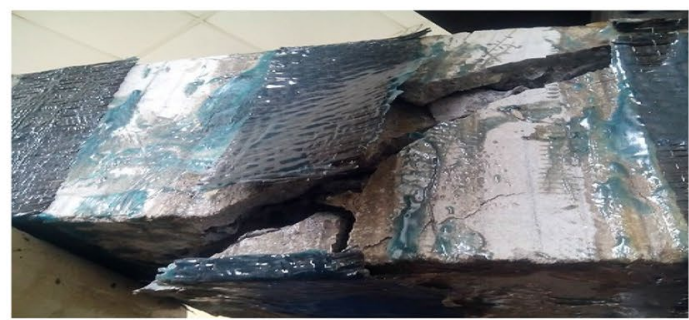

B4

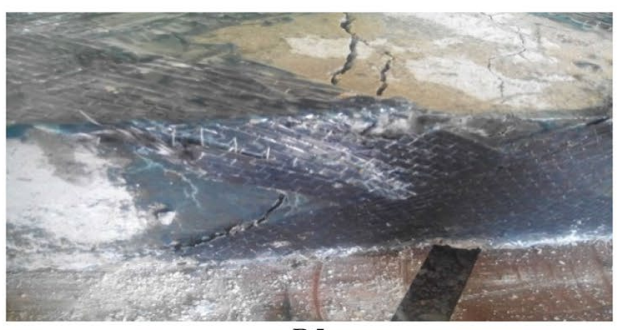

B5

Fig. 6 Strengthened beams after failure under bending

\section{SN Applied Sciences}


$30^{\circ}$ for all specimens, which is in agreement with the existing studies [32, 41, 42]. Debonding or rupture occurred when cracks in strip and cross-wrapped beam specimens passed through the CFRP strips. Most of the strips for B3 were debonded from concrete, which was initiated when the cracks reached the CFRP strips. Additionally, failure in the B4 and B5 specimens occurred simultaneously with the crushing of concrete and rupture of the CFRP strips.

\subsection{Interaction between internal stirrups and EB CFRP strips}

As EB shear reinforcement, CFRP is a common method for strengthening $\mathrm{RC}$ beams because it possesses high elastic modulus, which results in confinement at a certain scale and effective constraint of inclined tensile strains of concrete [32]. Therefore, inclined cracks due to shear were trapped by the EB CFRP strips, which ultimately increased load-carrying capacity. When steel stirrups undergo sufficient yielding, the debonding of CFRP prevented the steel stirrup from reaching yielding, which, therefore, decreased capacity. In the experimental results, the B3 and B4 beams were strengthened to increase the load-carrying capacity of beams by providing shear strength. In Fig. 6 , the B3 beam failed because the debonding that is initiated from the inclined shear cracks in concrete. Therefore, the internal steel cannot reach the yielding point and did not further contribute to the carrying load, which decreased load capacity. Again, a negative interaction was observed between internal steel stirrups and EB CFRP strips [33, 34]. That is, strong steel stirrups within beams can be transected by the critical shear cracks and constrain the effective utilization of the capacity of EB FRP $[32,34]$. This phenomenon occurred in the $B 3$ specimen because the internal steel and EB CFRP stirrup were on the same position. However, when steel stirrups transected the critical shear cracks and yielded under load, the cracks were widened significantly, leading to the occurrence of debonding in CFRP. Meanwhile, the steel and CFRP stirrups were alternately placed for the B4 specimen. Therefore, when the steel yielded and shear cracks widened progressively, the CFRP strips absorbed the tensile stress along the soffit of the beams and finally ruptured due to failure load. For this reason, the B4 beam can takes $25 \%$ more load than B3 and increase flexural capacity.

\section{Predicted versus experimental ultimate load-carrying capacity}

The predicted load capacity of flexurally strengthened B1CA and B1SA beams were calculated according to Eq. (1) and the guidelines for the CFRP-strengthened beams. Meanwhile, the load capacity of the shearstrengthened B3 and B4 beam specimens were calculated using Eq. (2) and the associated guidelines. Figure 7 provides the predicted and experiential load capacities of the four beams and control. In most of the cases, the experimental results showed larger values for load capacity than predicted ones, except for the B3 beam. The cause of lower capacity in the B3 beam is the early debonding and negative effect of the internal steel stirrups. According to the $\mathrm{ACl}$ 440.2R-17 guideline, approximately $40.4 \%$ shear for the B3 beam was predicted to be carried by the steel stirrups, and $46.4 \%$ will be carried by the CFRP sheets. However, the shear capacity of the CFRP sheet in the experiment was lower due to early debonding. Meanwhile, for the B4 specimen, $43.8 \%$ shear was approximated to be carried by the steel stirrups, and $42.2 \%$ will be carried by the CFRP sheets. Additionally, the experimental results showed general agreement with this approximation because the yielding and CFRP rupture proved that the beams have reached the ultimate point. In general, the guidelines given in $\mathrm{ACl}$ $440.2 R-17$ [35] for predicting the load capacity of flexurally and shear-strengthened beams by EB FRP sheets are relatively conservative. An increase in load capacity of 21.7-26.6\% was observed in the experimental test compared to the predicted capacity of flexurally strengthened beams. In addition, approximately an $18.8 \%$ increase in load-carrying capacity was observed for the B4 beam strengthened with strip wrapping. Meanwhile, a $10 \%$ lower result was predicted for the B3 beam, which failed at debonding during the early loading stage. Additionally, an improvement in load capacity at 34\% was estimated given the shear capacity of control beams compared with that for flexural strength capacity. This finding indicates that the $\mathrm{ACl} 440.2 \mathrm{R}-17$ [35] guidelines provide predictions close to the experimental results for shear capacity compared with flexural strength. Thus, an effective stress for CFRP sheets can be utilized for predicting of load capacity for flexure.

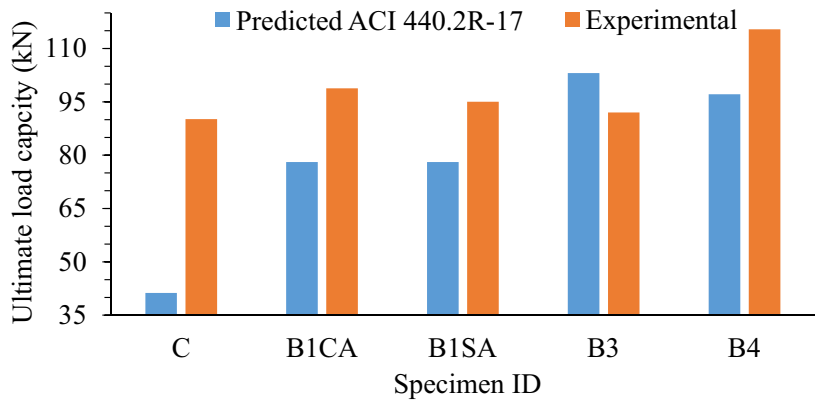

Fig. 7 Predicted and experimental load capacity variation for tested beams 


\section{Conclusions}

In this study, the load capacity of small-scale RC beams and corresponding flexural strength were evaluated after strengthening using CFRP sheets. The strengthening system differed in configuration, and concrete surface preparation techniques also varied in several cases. The test results on small RC beams showed a variation trend similar to the results obtained from different full-scale test studies. The following conclusions can be drawn on the basis of the results:

(1) The ultimate load capacity of all CFRP-strengthened beams is improved considerably. The amount of their enhancement depends on configuration and surface treatment. The increase in ultimate load capacity ranges between 1.7 and $60.9 \%$. This study reveals that the full-length $\mathrm{U}$-wrap system is suitable for flexural strengthening, and the strip U-wrap system, which is placed alternately with the internal stirrups, is best for shear strengthening.

(2) The strengthened beams showed high deflection values under ultimate and failure loads because of the EB CFRP layer. Therefore, the beams have more significant yield and ductility than the control one.

(3) The main failure modes of the strengthened beams include concrete crushing, rupturing, and debonding of the CFRP. FRP rupture was observed for highly effective strengthened system, such as the $\mathrm{B} 2 \mathrm{CA}$ and $\mathrm{B} 4$ beams, where the B2SA and B3 beams were debonded during the early loading stage and resulted in low strength development.

(4) The experimental ultimate load-carrying capacity of CFRP-strengthened RC beams were nearly the same as the predicted capacity based on the $\mathrm{ACl} 440.2 \mathrm{R}$ 17 guidelines, which provided conservative values for CFRP-strengthened RC beams relative to the experimental results.

\begin{abstract}
Acknowledgements This study was carried out at the Department of Civil Engineering, Pabna University of Science and Technology, Pabna 6600 , Bangladesh. The authors are grateful for the management, secretary, chairman, and faculty members of the Civil Engineering Department for providing facilities and cooperation.
\end{abstract}

Funding This research did not receive external funding.

\section{Compliance with ethical standards}

Conflicts of interest The authors disclose no conflict of interest.

\section{References}

1. Siddika A, Al Mamun MA, Alyousef R, Amran YHM (2019) Strengthening of reinforced concrete beams by using fiberreinforced polymer composites: a review. J Build Eng 25:100798. https://doi.org/10.1016/j.jobe.2019.100798

2. Al-Gemeel AN, Zhuge Y (2019) Using textile reinforced engineered cementitious composite for concrete columns confinement. Compos Struct 210:695-706. https://doi.org/10.1016/j. compstruct.2018.11.093

3. Huang L, Zhao L, Yan L (2018) Flexural performance of RC beams strengthened with polyester FRP composites. Int J Civ Eng 16:715-724. https://doi.org/10.1007/s40999-016-0140-0

4. Al-Mahaidi R, Kalfat R (2018) Methods of structural rehabilitation and strengthening. Rehabilitation of concrete structures with fiber-reinforced polymer. Elsevier, New York, pp 7-13

5. Siddika A, Shojib MHH, Hossain MM et al (2019) Flexural performance of wire mesh and geotextile-strengthened reinforced concrete beam. SN Appl Sci 1:1324. https://doi.org/10.1007/ s42452-019-1373-8

6. Huo J, Li Z, Zhao L et al (2018) Dynamic behavior of CFRPstrengthened reinforced concrete beams without stirrups under impact loading. ACI Struct J 115:775-787. https://doi. org/10.14359/51701283

7. Ou Y, Zhu D (2015) Tensile behavior of glass fiber reinforced composite at different strain rates and temperatures. Constr Build Mater 96:648-656. https://doi.org/10.1016/j.conbuildma t.2015.08.044

8. Bournas DA, Pavese A, Tizani W (2015) Tensile capacity of FRP anchors in connecting FRP and TRM sheets to concrete. Eng Struct 82:72-81. https://doi.org/10.1016/j.engst ruct.2014.10.031

9. Belarbi A, Acun B (2013) FRP systems in shear strengthening of reinforced concrete structures. Proc Eng 57:2-8. https://doi. org/10.1016/j.proeng.2013.04.004

10. Osman BH, Wu E, Ji B, Abdulhameed SS (2017) Repair of precracked reinforced concrete (RC) beams with openings strengthened using FRP sheets under sustained load. Int J Concr Struct Mater 11:171-183. https://doi.org/10.1007/s40069-016-0182-3

11. Rousakis $T$ (2013) Retrofitting and strengthening of contemporary structures: materials used. In: Beer M, Kougioumtzoglou IA, Patelli E, Au IS-K (eds) Encyclopedia of earthquake engineering. Springer, Berlin, pp 1-15

12. Garcez M, Meneghetti L, da Silva Filho LC (2008) Structural performance of $\mathrm{rc}$ beams poststrengthened with carbon, aramid, and glass FRP systems. J Compos Constr 12:522-530. https:// doi.org/10.1061/(ASCE)1090-0268(2008)12:5(522)

13. Obaidat YT, Heyden S, Dahlblom O (2010) The effect of CFRP and CFRP/concrete interface models when modelling retrofitted RC beams with FEM. Compos Struct 92:1391-1398. https://doi. org/10.1016/j.compstruct.2009.11.008

14. Moein RS, Tasnimi AA (2016) An analytical model for FRP debonding in strengthened RC beams under monotonic and cyclic loads. Int J Concr Struct Mater 10:499-511. https://doi. org/10.1007/s40069-016-0172-5

15. Chen W, Pham TM, Sichembe H et al (2018) Experimental study of flexural behaviour of RC beams strengthened by longitudinal and U-shaped basalt FRP sheet. Compos Part B Eng 134:114126. https://doi.org/10.1016/j.compositesb.2017.09.053

16. Shannag MJ, Al-Akhras NM, Mahdawi SF (2014) Flexure strengthening of lightweight reinforced concrete beams using carbon fibre-reinforced polymers. Struct Infrastruct Eng 10:604-613. https://doi.org/10.1080/15732479.2012.757790

17. Pham TM, Hao H (2017) Behavior of fiber-reinforced polymer-strengthened reinforced concrete beams under 
static and impact loads. Int J Prot Struct 8:3-24. https://doi. org/10.1177/2041419616658730

18. Remennikov A, Goldston M, Neaz Sheikh M (2017) Impact performance of concrete beams externally bonded with carbon FRP sheets. In: Mechanics of structures and materials: advancements and challenges-Proceedings of the 24th Australasian conference on the mechanics of structures and materials, ACMSM24 2016, pp 1695-1699

19. Triantafyllou GG, Rousakis TC, Karabinis AI (2018) Effect of patch repair and strengthening with EBR and NSM CFRP laminates for RC beams with low, medium and heavy corrosion. Compos Part B Eng 133:101-111. https://doi.org/10.1016/j.composites b.2017.09.029

20. Singh SB (2013) Shear response and design of RC beams strengthened using CFRP laminates. Int J Adv Struct Eng 5:16. https://doi.org/10.1186/2008-6695-5-16

21. Ary MI, Kang THK (2012) Shear-strengthening of reinforced \& prestressed concrete beams using FRP: part I-review of previous research. Int J Concr Struct Mater 6:41-47. https://doi. org/10.1007/s40069-012-0004-1

22. Mostofinejad D, Tabatabaei Kashani A (2013) Experimental study on effect of EBR and EBROG methods on debonding of FRP sheets used for shear strengthening of RC beams. Compos Part B Eng 45:1704-1713. https://doi.org/10.1016/j.composites b.2012.09.081

23. Charalambidi BG, Rousakis TC, Karabinis Al (2016) Fatigue behavior of large-scale reinforced concrete beams strengthened in flexure with fiber-reinforced polymer laminates. J Compos Constr 20:04016035. https://doi.org/10.1061/(ASCE)CC.19435614.0000689

24. Kang THK, Howell J, Kim S, Lee DJ (2012) A state-of-the-art review on debonding failures of FRP laminates externally adhered to concrete. Int J Concr Struct Mater 6:123-134. https ://doi.org/10.1007/s40069-012-0012-1

25. Bilotta A, Ceroni F, Di Ludovico M et al (2011) Bond efficiency of EBR and NSM FRP systems for strengthening concrete members. J Compos Constr 15:757-772. https://doi.org/10.1061/(ASCE) CC.1943-5614.0000204

26. Hawileh RA, Rasheed HA, Abdalla JA, Al-Tamimi AK (2014) Behavior of reinforced concrete beams strengthened with externally bonded hybrid fiber reinforced polymer systems. Mater Des 53:972-982. https://doi.org/10.1016/j.matdes.2013.07.087

27. Firmo JP, Arruda MRT, Correia JR, Rosa IC (2018) Three-dimensional finite element modelling of the fire behaviour of insulated RC beams strengthened with EBR and NSM CFRP strips. Compos Struct 183:124-136. https://doi.org/10.1016/j.compstruct 2017.01.082

28. El-Ghandour AA (2011) Experimental and analytical investigation of CFRP flexural and shear strengthening efficiencies of RC beams. Constr Build Mater 25:1419-1429. https://doi. org/10.1016/j.conbuildmat.2010.09.001

29. Mostofinejad D, Talaeitaba SB (2014) Strengthening and rehabilitation of RC beams with FRP overlays under combined shear and torsion. Electron J Struct Eng 14:84-92
30. Ghobarah A, Ghorbel MN, Chidiac SE (2002) Upgrading torsional resistance of reinforced concrete beams using fiber-reinforced polymer. J Compos Constr 6:257-263. https://doi.org/10.1061/ (ASCE) 1090-0268(2002)6:4(257)

31. Pham TM, Hao H (2016) Impact behavior of FRP-strengthened RC beams without stirrups. J Compos Constr 20:04016011. https ://doi.org/10.1061/(ASCE)CC.1943-5614.0000671

32. Rousakis TC, Saridaki ME, Mavrothalassitou SA, Hui D (2016) Utilization of hybrid approach towards advanced database of concrete beams strengthened in shear with FRPs. Compos Part B Eng 85:315-335. https://doi.org/10.1016/j.composites b.2015.09.031

33. Ebead U, Saeed H (2017) FRP/stirrups interaction of shearstrengthened beams. Mater Struct 50:103. https://doi. org/10.1617/s11527-016-0973-7

34. Chen GM, Teng JG, Chen JF (2012) Shear strength model for FRP-strengthened RC beams with adverse FRP-steel interaction. J Compos Constr 17:50-66. https://doi.org/10.1061/(ASCE) CC.1943-5614.0000313

35. $\mathrm{ACl}$ Committee 440, American Concrete Institute, $\mathrm{ACl}$ Committee 440 (2017) Guide for the design and construction of externally bonded FRP systems for strengthening concrete structures. American Concrete Institute

36. IS:8112-2013 (2013) IS 8112: 2013, Ordinary Portland Cement, 43 Grade-specification, Bureau of Indian Standards, New Delhi, Bur Indian Stand Delhi

37. ASTM C78/C78 M - 18 Standard Test Method for Flexural Strength of Concrete (Using Simple Beam with Third-Point Loading). https://www.astm.org/Standards/C78.htm. Accessed 27 Feb 2019

38. Teng JG, Chen JF, Smith ST, Lam L (2003) Behaviour and strength of FRP-strengthened RC structures: a state-of-the-art review. Proc Inst Civ Eng Struct Build 156:51-62. https://doi. org/10.1680/stbu.2003.156.1.51

39. Pham TM, Hao H (2016) Review of concrete structures strengthened with FRP against impact loading. Structures 7:59-70. https ://doi.org/10.1016/j.istruc.2016.05.003

40. Baggio D, Soudki K, Noël M (2014) Strengthening of shear critical RC beams with various FRP systems. Constr Build Mater 66:634644. https://doi.org/10.1016/j.conbuildmat.2014.05.097

41. Sas G, Täljsten B, Barros J et al (2009) Are available models reliable for predicting the FRP contribution to the shear resistance of RC beams? J Compos Constr 13:514-534. https://doi. org/10.1061/(asce)cc.1943-5614.0000045

42. Pellegrino C, Vasic M (2013) Assessment of design procedures for the use of externally bonded FRP composites in shear strengthening of reinforced concrete beams. Compos Part B Eng 45:727741. https://doi.org/10.1016/j.compositesb.2012.07.039

Publisher's Note Springer Nature remains neutral with regard to jurisdictional claims in published maps and institutional affiliations. 